\title{
Using Of Various Types of Consumer Containers in Technologies of Food Production
}

1,2,3,4 Odessa National Academy of Food Technologies, Ukraine, Odessa

\author{
"Correspondence author \\ Yakov G. Verkhivke \\ Professor \\ Odessa National Academy of Food Technologies \\ Ukraine \\ Odessa \\ E-mail : yaverkhivker@gmail.com
}

Submitted : 7 March 2020 ; Published : 26 March 2020

\begin{abstract}
Annotation: Successful sales of food products include reliable, safe and aes-thetically pleasing packaging. The buyer prefers plastic containers. When food products packed in various types of polymer containers, there are problems such as vacuum deformation of the packaging, industrial sterility of canned food, which can be solved using various technological methods and parameters.
\end{abstract}

Keywords: Food Technology, Polymer Packaging, Canning Methods, Thermal Sterilization, Vacuum Deformation

\section{Introduction}

In food production the ultimate aim of any technology is to obtain high-quality finished products in high-quality consumer packaging. The main conditions for successful sales of food products include high quality products and affordable prices, reliable, safe and aesthetically attractive packaging. Various materials are currently used for transportation, storage and identification of finished prod-ucts - from traditional cardboard and glass, metal to innovative polypropylene with a barrier layer.

Packaging safety should be ensured by: sanitary and hygienic indicators of the materials used for its production (the volume of certain chemicals, which is emitted from the package should not exceed permissible concentrations); me-chanical indicators (the container must withstand compressive force, hydro-static pressure, shock, tensile load and other effects in accordance with applica-ble standards); indicators of chemical resistance (packaging must be resistant to corrosion, oxidation, etc.) requirements for the circulation of goods on the market (storage, transportation, disposal standards). Consumer properties: to be practical (to provide convenient product extraction, compact placement of packaging in the refrigerator during storage, etc.) and aesthetic (colorful, attrac-tive).

As much as possible food cans of glass, metal, and polymer correspond to the listed requirements and are in demand among the consume. Its are used for packaging of any food products, including juices, juice-containing drinks, and mixed drinks $[1,2]$.

The most widely used containers and packaging are used for the production of long-term food products - canned food.

There are three main thermal preservation methods for protecting products from spoilage.

\section{Sterilization (pasteurization):}

Hermetically sealed in a consumer packaging food product is sterilized at a temperature of $100-120^{\circ} \mathrm{C}$. In a continuous pasteurizer, the product is aged at a pasteurization temperature of $75-100^{\circ} \mathrm{C}$ for a certain pasteurization time. After sterilization, canned food is intensively cooled.

\section{Hot bottling:}

Consistent products (juices, mashed potatoes, tomato paste) with high active acidity are sometimes preserved by hot bottling. The product is sterilized at temperatures of $85-95^{\circ}$ $\mathrm{C}$, then hot-packed in pre-prepared large metal, glass, polymer containers (with a capacity of $3 \mathrm{dm} 3$ or $10 \mathrm{dm} 3$ or more, corked and without subsequent sterilization in special equipment the container is sent for storage. Because of large volume of the product in the container, it is slowly self-cooling and at the same time its self-sterilization, so that microbio-logical stability is achieved.

Heating causes qualitative changes in canned food. Prolonged 
heating with rela-tively low temperature negatively affects the quality of the product than short-term heating at high temperatures. On this basis, a method of high-temperature short-term sterilization aseptic conservation was developed.

\section{Aseptic preservation:}

During aseptic preservation a product homogeneous in consistency is briefly sterilized in a thin layer of a stream at elevated temperature, quickly cooled and packed in sterile container in aseptic conditions, without the use of autoclaves or pasteurizers. The aseptic conservation method has several significant ad-vantages, one of which is the maximum preservation of the initial properties of the product (organoleptic, nutritional value) regardless of the volume of the container and a significant reduction in the duration of the heat treatment of the product.

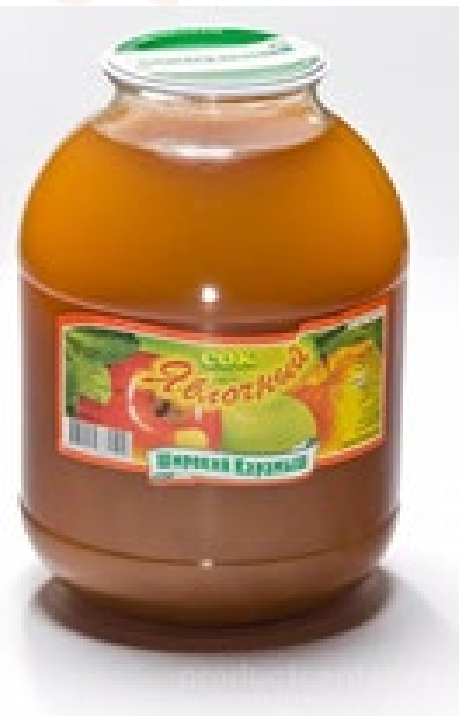

Glass containers - consumer products from this traditional packaging material for various food products are absolutely safe and environmentally friendly. The disadvantages of containers are its lack of mechanical strength (high fragility), significant weight (up to $30 \%$ gross) and the high cost of the container itself and its transportation. Lightweight glass reduces material consumption and $\mathrm{CO}_{2}$ emissions, making lightweight bottles popular in the non-alcoholic industry.

Now they use glass containers of type I closures for canning food products. This container is known as CKO (glass canned break-in). For these ones are made co-vers with a sealing rubber ring. During rolling, the roller of the capping machine bends the edges of the lid around the rim, while the rubber ring is sealed and provides sealing of the can.

Container CKO has a high strength capping. The capping method is simple, but opening such cans is difficult.

Glass containers of type III or "Twist-off" are sealed by screwing a threaded cap with a sealing polymer paste, which is located on the inner peripheral surface of the cap.

Glass bottles are sealed with caps with crown edges (CCM glass containers, crown caps) with a cortical or polyethylene gasket, as well as screw caps of type Ш.

Lids for all types of glass containers are made of white or lacquered tin or alu-minum. For drinks, mixed drinks, the most common type of glass containers on the market and among manufacturers is narrow-necked, wide-necked bottles of various capacities of $200-1000 \mathrm{~cm}^{3}$.

According to experts, nine out of ten European consumers consider glass pack-aging the most suitable for luxury goods, they say that it is a "classic". The most popular of the produced bottles are with volumes of 500,700 and $750 \mathrm{~cm}^{3}$. Bottleswith $500 \mathrm{~cm}^{3}$ accounts for about $50 \%$ of the market. The popularity of a bottle of this capacity is due to its versatility. The significant assortment of strong alcohol, beer, soft drinks and ketchups is poured into such containers.
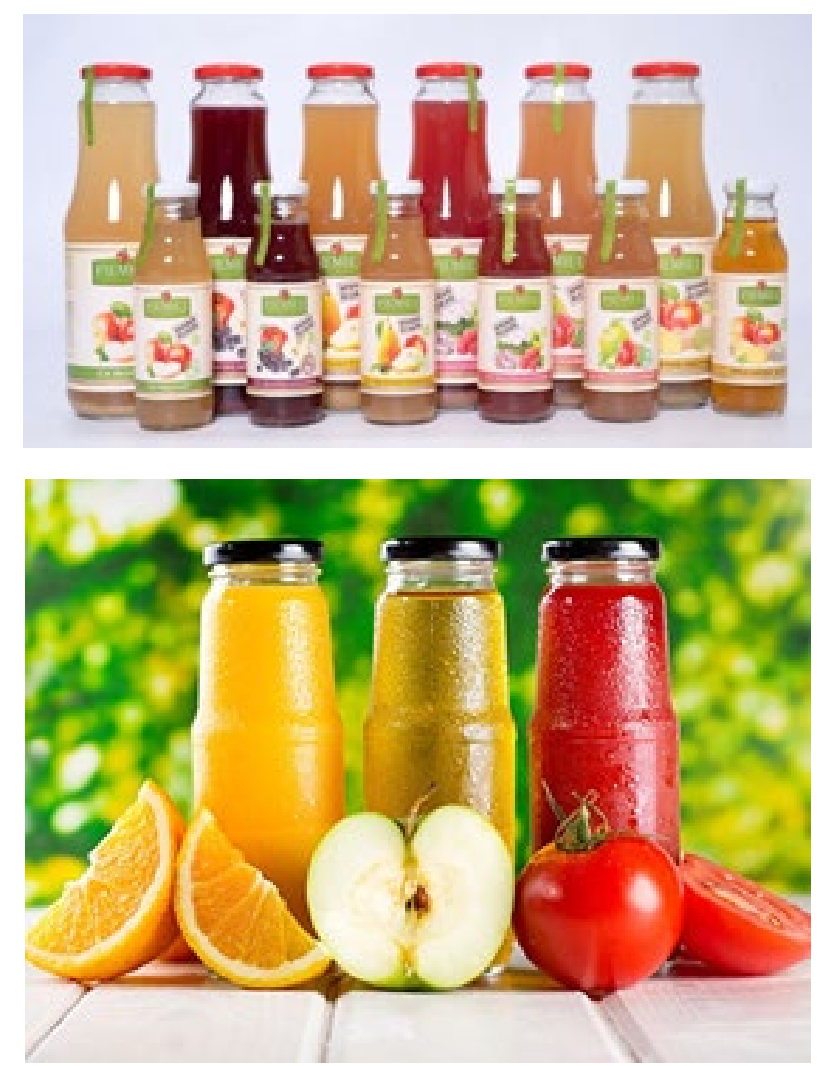

Metal containers - containers made of tin, aluminum, other metals and its alloys are widely used in the packaging of canned products. It reliably protects prod-ucts from mechanical stress and oxidation. Its faults: high cost, small assortment and insufficient safety for human health (in case of violation of production and technics of using by consumers). The most common metal containers, for ex-ample, for juices and drinks (alcoholic, nonalcoholic) including carbonated ones, are aluminum packaging. An aluminum does not rust like iron or even copper, and there are technologies and plants for its disposal that exist and are used, and this is an attempt to change the tradition of bottling in cardboard packaging, namely, packaging in aluminum cans following the example of car-bonated drinks. Basically, juice-containing products, mixed drinks, drinks like Coco-cola, beer (except juices) can be bottled in such cans. Juices have high acid-ity and it's technologically difficult to store in aluminum containers. 

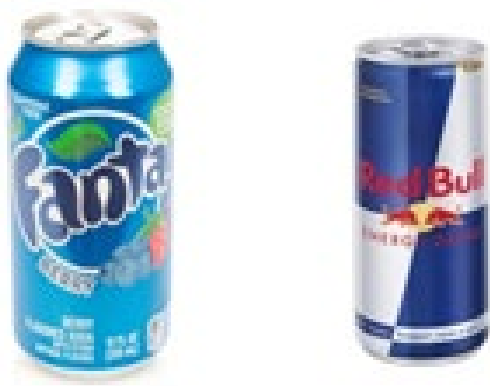

As known, the buyer prefers polymer packaging and this packaging is in maxi-mum demand among the population. The advantages of such materials are af-fordable cost, easiness of processing of returnable packaging and transporta-tion, compatibility with the production of a wide range of various products. Therefore, plastic products are used most widely. The main disadvantages of such consumer packaging are low environmental friendliness; transmission of plastic sunlight; quite high gas permeability.

Depending on the materials. Which are used, and accordingly on the mechani-cal stability and degree of strength, packaging materials are divided into hard, semi-rigid and soft.

1. The first place in the world for soft drinks is occupied by TETRA-RASK con-tainers, semi-rigid combination containers. As semi-rigid, this package retains its original shape and dimensions when filled with products. It is able to with-stand small mechanical stresses during transportation and storage. Provides protection of contents from mechanical influences, and in some cases - from the effects of oxygen, microflora, and ultraviolet radiation.

Combined packaging - obtained by the joint use of polymers, paper or other ma-terials (foil, cardboard). An aseptic preservation method is used for it - the product and containers are sterilized (by various methods, separately from each other), and then the package is filled with products and sealed under ster-ile conditions. Such processing can significantly extend the shelf life of goods without the use of preservatives, preventing the loss of its consumer properties.

This container is environmentally friendly, allows you to aseptically store drinks, pack them in batches, "play" with types of lids, and in addition, provides almost unlimited possibilities for creativity - the design can be any, Widely used and shape options - for example, Tetra Pack in addition to the most common packaging Tetra Brick also offers more complex, but at the same time more er-gonomic and comfortable (albeit more expensive) Tetra Prisma and Tetra Gem-ina. The juices and nectars of the premium segment are also distinguished in terms of packaging by a more detailed and carefully designed.
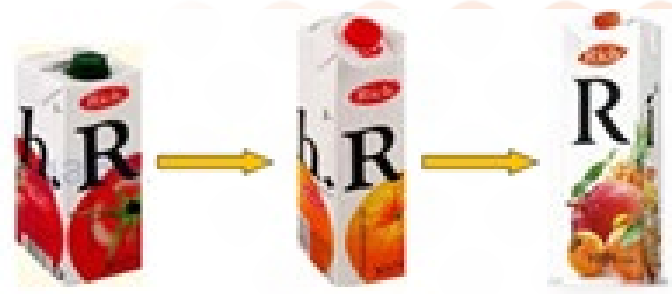

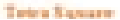
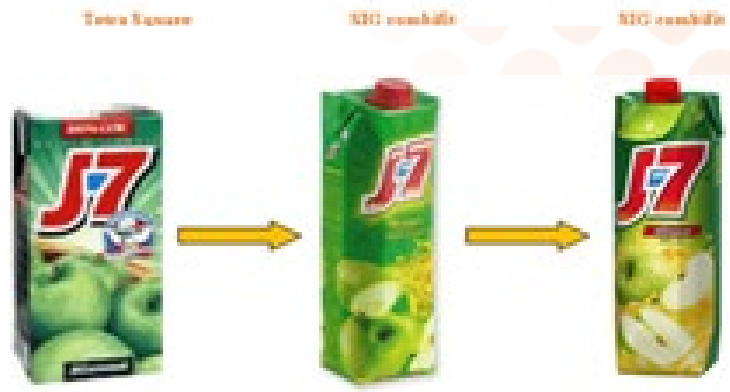

Teos ithel

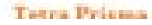

Totra Dikse:

There are two technologies for the formation of cardboard packaging. The first technology, which requires a large initial investment, is the formation of packag-ing from the so-called roll. It is used to form the Tetra-Brik of Tetra-Pack. The second technology used by a number of manufacturers in the world is the molding of a package from die cutting (a kind of "flat bag"): a method that can significantly reduce initial investment in equipment.
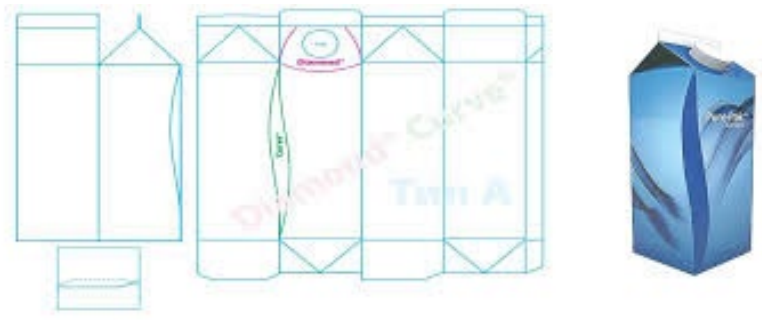

According to TetraPak, this type of container accounts for $85 \%$ of the bottling of beverages in the world.

2. Second place in the market is occupied by semi-rigid blown containers of type PET.

This package is suitable for packaging liquid, pasty and other products, car-bonated drinks. It is made of various thermoplastics and represents preforms from which bottles can be blown when preforms are heated to $100^{\circ} \mathrm{C}$. This packaging is called PET packaging - polyethylene terephthalate (the polymeric material from which this packaging is made).

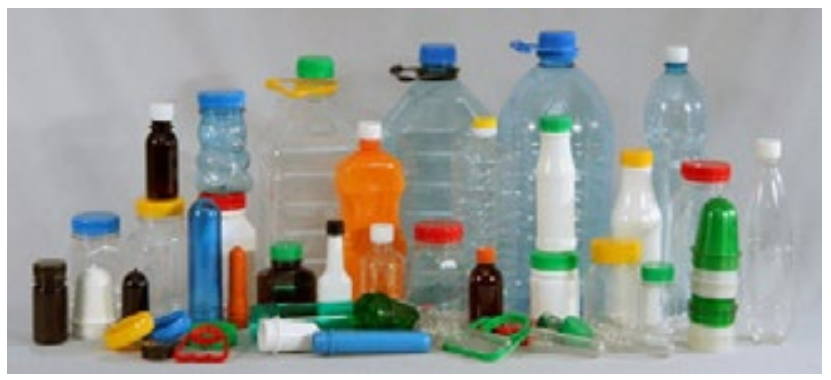


This package using forconservation juices and drinks and using various techno-logical methods: Thermal sterilization (PET packaging is used, which with-stands high temperatures);

\section{Aseptic conservation; \\ Chemical preservatives.}

Over the next 10 years (to 2030), PET consumption in the juice beverage indus-try is expected to grow by $140 \%$. This forecast is based primarily on the prem-ise that PET containers will meet the requirements of juice producers. Cold pas-teurization (application of the technology of cold electronic pasteurization of products (irradiation) - during packaging, avoids the use of preservatives and heat when packing juices in PET bottles.
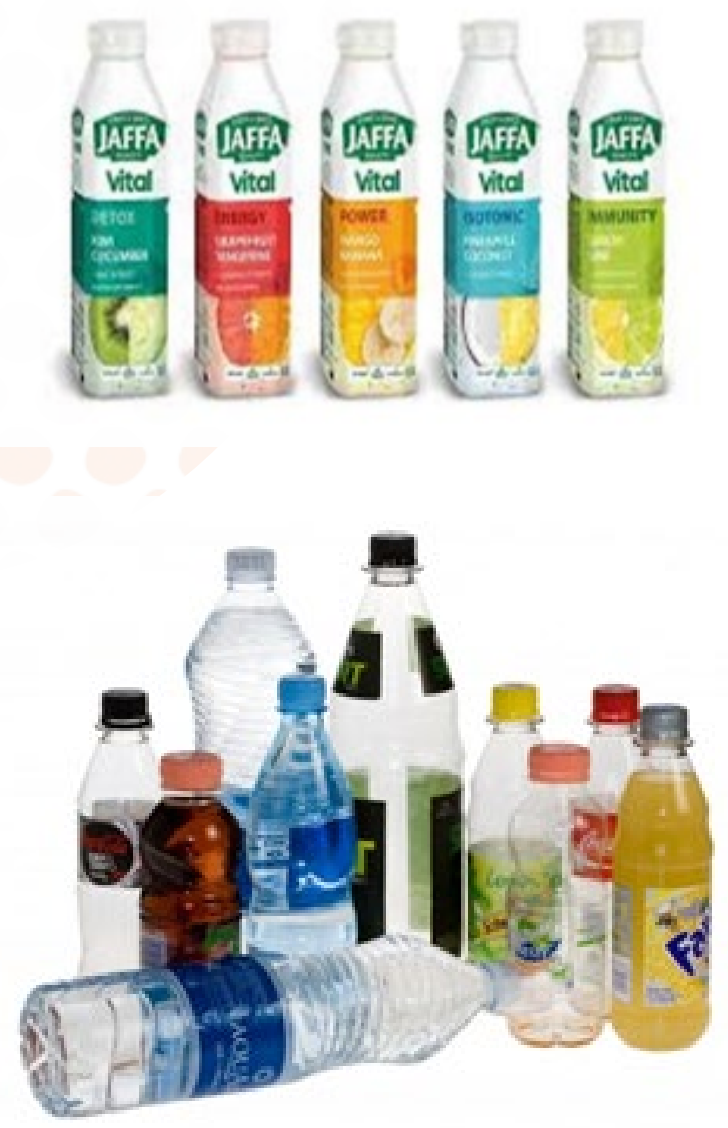

This type of container is used for canning juices, na3. Soft polymer packaging type Doy Pack.

This container changes shape and size when filled with products. Depending on the production technology, the packaging can be blown, injection molded and pressed, thermoformed and welded. The universal materials that can be used in the manufacture of containers using all these technologies are polymers.

Soft packaging - polymer (bags, bags) belong to this type. The advantages of such containers are low purchase and delivery costs, as well as the possibility of sealing to prevent oxidation of packaged food.
Doy Pack is a special type of flexible vacuum packaging, which is a plastic bag with a bottom, which allows the packaging to stand upright in a filled form. The main feature of the Doy-Pack is a multi-seam (from 1 to 5) design with a flexible bottom. Doy Pack bags are made from thin, but very durable polymer films con-taining several layers of material. As a rule, Doy Pack packages are made of 2 - 4-layer combined materials. The combination of different layers in the manufac-ture of films for the Doy-Pack package allows you to obtain the desired proper-ties of the finished package, such as a combination of high strength and elastici-ty with a low package weight. For the manufacture of the package, a laminated film with a thickness of 100-120 $\mu \mathrm{m}$ is used, which has several layers: the inner one is made of polyethylene, it ensures the stability of the packaging and heat sealability of the seams, and the outer, mylar (PET) layer is convenient for ap-plying flexographic or deep roto printing. An intermediate layer of aluminum foil is sometimes used as a barrier, which is important when packing juices.
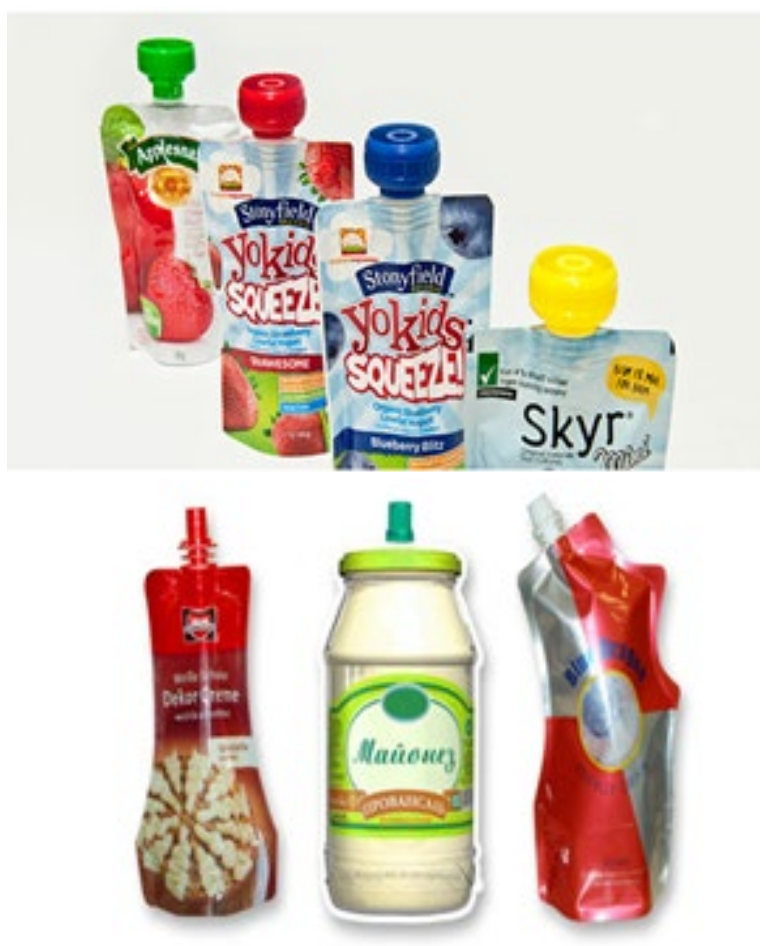

Preservation methods for packaging DOY PAK are aseptic and hot filling.

The retort bags that appeared relatively recently in the practice of the food in-dustry make it possible to combine the advantages of "soft" packaging with the advantages of sterilized food products, since the packaging material from which they are made not only occupies no more than $5 \%$ of the mass of the finished product, but also allows for final heat treatment - sterilization of products at high temperatures in both steam and water.

A retort bag is a food package used as an alternative to cans in the manufacture of canned food. The retort package consists of several laminated layers that can withstand high temperatures 
during sterilization in an autoclave.

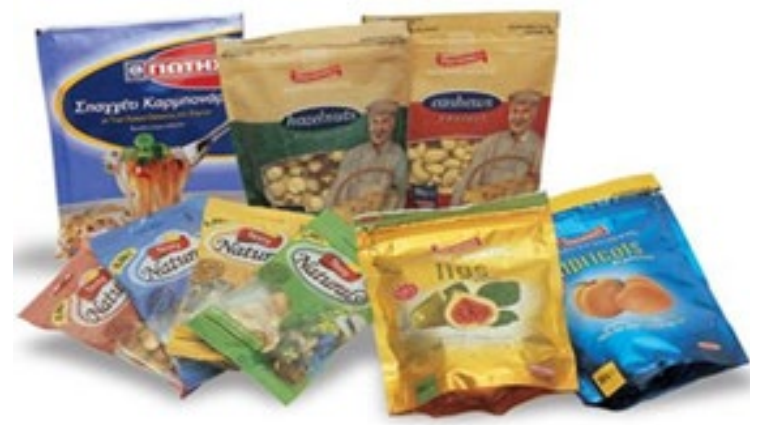

4. Rigid packaging retains its original shape and size when filled with products. It is able to withstand mechanical stress during transportation and storage. Products from polymer type (barrels, boxes) fall into this category. Such pack-aging for food products provides protection of the contents from mechanical influences, and in some cases also from the effects of oxygen, microflora, and ultraviolet radiation. It should be remembered that a rigid container has a large weight (25-30\% gross), as well as a significant cost.

For juices and drinks, rigid packaging is presented in Bagin-Box type contain-ers. Bag-in-Box enables juice producers to deliver their products to where they need them in the most economical way, in conditions of safety, stability and preserving the natural properties, despite the fact that the product stays fresh to the last drop. Bag-in-Box increases the shelf life of juice after opening the package, ensuring its freshness for a long time. Soft plastic bags with juice are placed in metal or polymer, cardboard rigid boxes, barrels or containers that protect the product during transportation from mechanical stress.
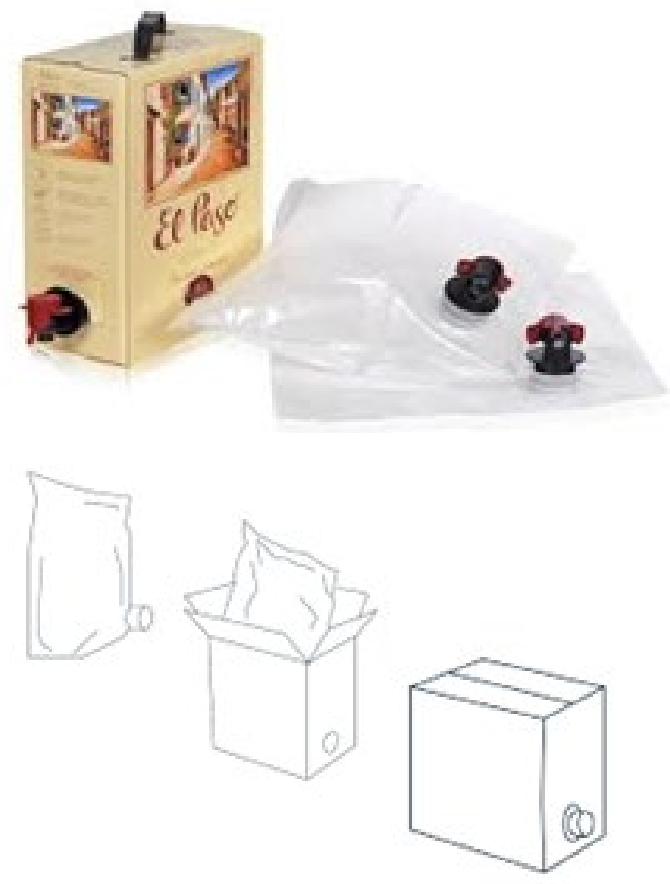
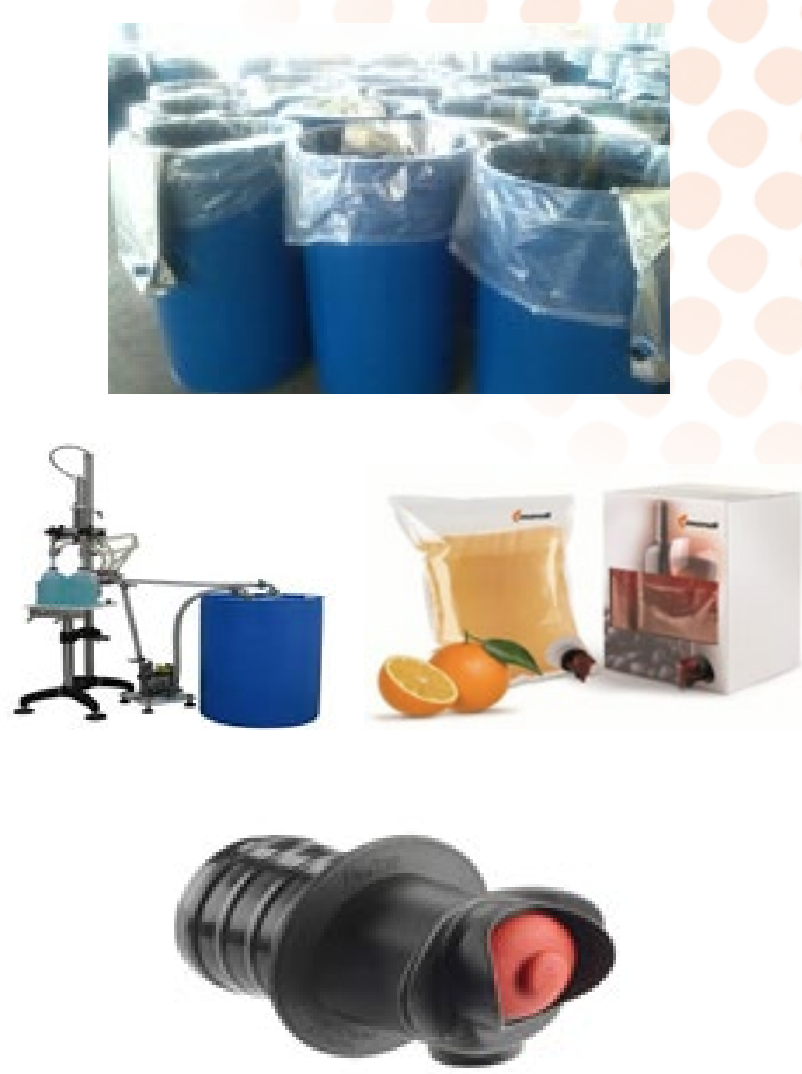

Juices, nectars and juice-containing drinks are bottled and delivered to the final consumer through a retail network in 3-liter multilayer bags, which protect the contents from penetration of oxygen, odors and other external irritants. Juices in larger bags (5, 10, 15 and 20 liters) are delivered to hotels, restaurants, cafes, fast-food enterprises, schools and kindergartens. The possibility of using juices, nectars and juice drinks in Bag-in-Box packaging for feeding children in organized groups is confirmed by the Ministry of Health. The latest commercially generationof cover with tap - Flex tap provides the beginning of dosing of the product at the touch of a button and its automatic stop when the button is re-leased, allows you to control the flow rate and has excellent ergonomics.

\section{Standard Types of Fillms}

$\mathrm{HyBar}^{\circledR}$ metallized film is designed to provide the necessary protection of the product from exposure to oxygen and light. Depending on the modification, the film can be used for products poured at room temperature, requiring hot filling, as well as filling under aseptic conditions.
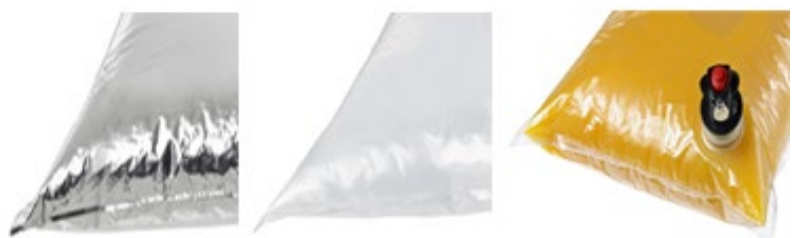

Clear Shield ${ }^{\mathrm{TM}}$ transparent film is a multi-layer coextruded barrier film that provides reliable and tight joints, overall package strength and product protec-tion against oxygen. 
Depending on the specification, Clear Shield ${ }^{\mathrm{TM}}$ can be used for hot and aseptic filling.

5. Today, innovative technologies in the field of juices and drinks, containers are presented on the US market. American companies prefer to produce cold-storage juices, which are freshly squeezed drinks, with a shelf life of no more than 3 days.

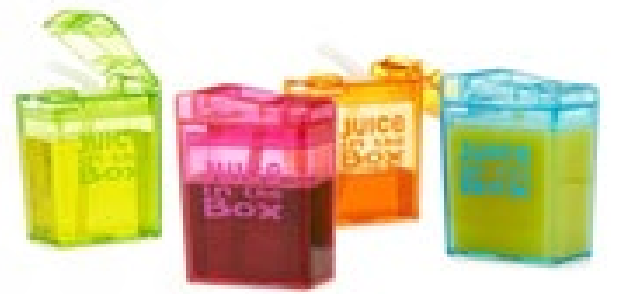

Such juices are packaged in large plastic canisters with a capacity of 2 liters or more. With a slightly longer shelf life - about a month - pasteurized juices are common in the USA. The share of such products in the US market reaches $50 \%$ and is packaged in cardboard boxes (with a capacity of 1 liter or more) with a screw cap - Tetra Top.

As studies have shown, a modern buyer prefers polymer packaging and this packaging is in maximum demand among the population. The same group in-cludes products from polystyrene (cups for drinks, containers for various food products, regardless of consistency), polypropylene (cups for fermented milk products), polyvinyl chloride (containers, bottles), polyethylene terephthalate (containers for salads, bulk products) and others polymers. The advantages of such materials are affordable cost, ease of processing of returnable packaging and transportation, compatibility with the production of a wide range of vari-ous products. The main disadvantages of such consumer packaging are low en-vironmental friendliness; transmission of plastic sunlight; quite high gas per-meability. The packaging of multilayer polymeric materials can also be included in the polymer packaging. For example, polypropylene containers with a high barrier layer. Such packaging allows the products to provide a significantly higher degree of protection against the penetration of oxygen and pollutants from the outside, for a long time to preserve the aroma and freshness of prod-ucts, it is distinguished by reliability, low weight and presentable appearance. Packaging materials largely determine its types and production technologies [3].

Packing from gas-filled materials - such containers (trays, cans, containers) are made of polymers that can withstand high loads and temperature extremes. It is characterized by light weight, economy, provides protection of goods from both mechanical damage and moisture, exposure to microorganisms.

Combined packaging - obtained by the joint use of polymers, paper or other ma-terials (foil, cardboard). Such containers allow a long time to store products, preventing the loss of its consumer properties. This type includes the following types of food packaging:

Flow and skin packaging, shrink and stretch films. A "flow" type container is ob-tained by applying molten polymer to packaged goods, and a "skin" is formed using shrink films that are applied to the product (with or without a substrate). Then the material is heated, compressed and begins to tightly fit the product. Such containers are used for packaging meat, fish, vegetables and fruits.

The blister pack consists of a rigid substrate and a plastic case, which has the shape of a hemisphere or repeats the shape of the product. Such a cased to the base by welding, glue or staples. In such containers canned fish, pastes and oth-er products can be stored.

For liquid products (juices, dairy and soy products), aseptic polymer combined packaging technology is most often used. Vacuum polymer combined packaging is suitable for meat and fish products, while polymer packaging technology us-ing a gas-modified medium has been increasingly used for fruits and vegetables $[4,12,13,14]$.

\section{Research Purpose}

Development of technological conditions of use and processing parameters for various types of cans. At the same time, different methods of canning food products were used, as well as their combination.

\section{Research Results and Discussion}

Development of pasteurization regime parameters for various methods of pre-serving products in a polymer container of the Doy-Pak type.

Products for research were tomato sauces and ketchups, which were packaged in small consumer plastic containers of the "Doy-Pak" type, of various capaci-ties.

Doy-Pack packages (flat, standing packages) belong to soft polymer containers, in which food preservation is growing every year. Flat bags can be made of or-dinary film material with four or three welds, of tubular material with two transverse welds or two transverse seams and one longitudinal. The container withstands high packing temperatures, pasteurization temperatures, is conven-ient to use and transport $[5,6]$.

In the first version, a combination of two preservation methods is used - ther-mal sterilization by the "hot bottling" method and the use of preservatives. Moreover, the product packaged in small consumer plastic containers of the "Doy-Pak" type is subjected to heat treatment in such a way that $100 \%$ of the required sterilizing effect is not achieved. Missing mortality is ensured through the use of preservatives (sorbic acid), which ensures industrial sterility of the product and more complete preservation of the nutritional and nutritional val-ue of finished products. 
In the second version, only the aseptic method of preserving tomato sauces and ketchups in the Doy-Pak container is used, pasteurization parameters for this assortment have been developed, which made it possible to obtain industrially sterile products.

When using this technology, the assortment of canned food, containers, a num-ber of conditions must be strictly observed, which will ensure the production of industrially sterile and highquality products: when packing canned food, the temperature and $\mathrm{pH}$ of the product must be observed, the type of equipment for sterilization must be taken into account, auxiliary materials (e.g. spices, spic-es, preservatives), containers (blowing doypack packages with sterile air, pro-cessing of the cap-lid of the container and others).

Research has been conducted and parameters developed using PET plastic con-tainers in the food industry.

At food enterprises, for the packaging of alcoholic, nonalcoholic drinks, vegeta-ble oils, polymeric consumer containers made of polyethylene terephthalate (PET) are very widely used.

A food manufacturer who uses even non-hot products for packaging this type of container has a problem with vacuum deformation of the container, which occurs when the technology is violated.

The presence of vacuum deformation in a polymer container with a product leads to its non-commercial appearance (the side surface of the container can be pulled in, the bottom of the bottle becomes convex and the container loses sta-bility), the manufacturer also has problems with the sale of finished products, storage and transportation. Production studies were conducted, as a result of which technological methods were proposed for eliminating the phenomenon of vacuum deformation of polymer consumer packaging.

The vacuum deformation of a PET plastic container when packing liquid, not hot, homogeneous, calm products is caused by several reasons: use in the pro-duction of thinwalled polymer bottles (insufficient wall thickness of the bottles); Mismatch of the topography of the container body to technological condi-tions (the required number of stiffeners on the surface of the bottles); Tempera-ture difference between the product and the conditions of its packaging; The absence of excess pressure or an uncritical amount of vacuum in a hermetically sealed bottle; Insufficient value of the degree of filling of the container with the product.

Upon receipt of polymer packaging at the enterprise, it is necessary to control the wall thickness and the mass of bottles. The value of these indicators should correspond to the normative values in accordance with the current technologi-cal documentation.

If an enterprise produces polymer containers from a preform, it is necessary to control the mass of the preform itself, the weight of the preform is determined mainly by the final capacity of the finished bottle to be made from this preform, as well as the thickness of the walls of the bottle. The wall thickness of the fin-ished bottle should prevent the occurrence of vacuum deformation of the con-tainer [15].

The relief of the outer surface of the polymer bottle depends on the design of the mold for blowing the bottles in the appropriate equipment. Therefore, this issue must be monitored when purchasing this equipment.

When filling the product into this type of container, it is necessary to control the difference between the temperature of the product and the temperature condi-tions when packing (temperature in the technological workshop, bottle temperature, room temperature for the product storage, product filling temperature.

The temperature difference should not exceed the standard value, therefore, it is necessary technically control the required values of this parameter and use technological methods to maintain it (heating or cooling of the product, sup-ported by ie the desired temperature in the workplace, etc.).

In order to prevent vacuum deformation, an inert gas can be introduced into the bottle with the product when corking and excessive pressure can be created inside the sealed package, which will not allow changing the negative shape of the container - the process of displacing oxygen from the container and re-placing it with an inert gas (nitrogen). This technology reduces the level of oxy-gen in the container, thereby reducing the degree of oxidation of the product with atmospheric oxygen, which helps to improve its consumer properties (taste, color, consistency), extend shelf life, and improve presentation.

Overpressure in the container contributes to: an increase in its rigidity, which makes it possible to form transport bags that are more overall in height, with products in PET bottles, without fear of deformation of the lower layer of the product, reduce logistics costs, prevent vacuum deformation of the PET packag-ing during packaging of products - a calm product is packed in a PET bottle and immediately sealed, while the pressure in the hermetically sealed bottle with the product is higher than atmospheric, which prevents vacuum deformation of the container, if the pressure in the container is much lower than atmospheric, then the side the surface of the bottle is retracted, the shape of the container be-comes non-standard and vacuum deformation occurs.

Control of the degree of filling of the container with the product will prevent packaging deformation. The degree of filling of the container with the product is the difference between the full volume of the bottle and the volume of empty space in the container. Calculations and studies have shown that the relation-ship between the degree of filling and the occurrence of deformation of the bot-tles is this: the higher the 
degree of filling of the container with the product, the smaller the volume of the space that is not filled with the product, the lower the vacuum value and the less the probability of vacuum deformation. But this in-dicator affects the net mass of the product in the container, so there should be a correlation between these indicators [7.8]. The target industrial consumers of this technology are food enterprises using PET polymer consumer packaging for filling homogeneous, non-hot products.

Carried out industrial research and research on the optimal parameters and application conditions for preserving the products of glass containers, type $\amalg$, threaded.

This type of container is mainly used at food enterprises, as it is easily opened, aesthetic, is in unlimited demand by the consumer and manufacturer, and is the No. 1 glass container on the world market.

For the effective use of this type of packaging in production, it is necessary to comply with a number of mandatory requirements, otherwise its use becomes unprofitable (physical, microbiological marriage of products): Sh type contain-ers and a lid for canning are used only new ones, in accordance with the current scientific and technical documentation for this type of finished product. It is forbidden to use this type of container for canning a second time, not a new or used can or lid.

Upon receipt of a glass jar from a manufacturer's factory at the entrance control of a threaded container, in accordance with the current regulatory document for this type of product, it is necessary to especially monitor the strength of the Twist-off can closure, it is $0.07-0.13 \mathrm{MPa}$, as well as other indicators (for exam-ple, ovality of the neck, chipped surface of the neck rim), which affect the tight-ness of the container.

It is also necessary to control the quality coming to the plant from the manufac-turer of the lid for the threaded type containers, carry out incoming inspection of the cover in accordance with the current regulatory document.

When packing products, it is necessary to control: the degree of filling of type $\amalg$ containers with a product, mass, product mass in a can; the initial temperature or the temperature of filling the product, the temperature should be in accord-ance with the current technological instructions for the production of this as-sortment of canned food, since otherwise, a mismatch of the initial temperature of the product can lead to container depressurization during sterilization and to physical and microbiological defects of canned food.

The jars with the product, when corking, are subjected to thermal exhausting with water vapor, before being covered with a lid, superheated steam is sup-plied at the moment of the first contact of the lid with the whisk of the neck of the jar. It is necessary to control the vacuum in the container after capping with special equipment.
The sterilization process parameter is pressure (back pressure in the auto-clave), it is necessary to strictly comply with the pressure tables in the auto-clave, in accordance with the current technological instructions for the produc-tion of this assortment of canned goods. The pressure value in the autoclave should not exceed the tabulated values, otherwise it can lead to a punching of the sealing gasket with the packaging rim, during sterilization and turning of the lid on the neck of the can, and loss of its tightness.

\section{Conclusions}

To use, when preserving food products, polymer containers of the Doy-Pak type, a number of conditions must be strictly observed, which will ensure the production of industrially sterile and high-quality products: when packing canned food, the temperature and $\mathrm{pH}$ of the product must be observed, the type of equipment for sterilization must be taken into account, control the parame-ters of sterilization modes, prepare auxiliary materials, preservatives, in ac-cordance with the instructions. The vacuum deformation of PET plastic containers during packaging of liquid, not hot, homogeneous, calm products is determined by several factors that need to be controlled: the use of a thin-walled polymer bottle in production (in-sufficient wall thickness of the bottles), mismatch of the packaging topography to technological conditions (required number of ribs hardness on the surface of the bottles), the temperature difference between the product and the conditions of its packaging, the absence of excess pressure or uncritical vacuum in the seal chno corked bottle, insufficient quantity degree of filling product containers.

To obtain benign food products that are preserved in glass carvings? it is neces-sary to comply with the mandatory requirements for incoming control of this type of packaging and lids, technological parameters, as well as control the storage and transportation of finished products in containers of the type "Twist-off".

\section{References}

1. Polymer packaging https://znaytovar.ru/s/Polimernaya tara.html

2. Types and types of polymer packaging. https://knowledge.allbest.ru/ marketing/3c0a65635b2ad78b5c43b88421306d37_0. html

3. Verkhivker Ya G, Miroshnichenko EM (2018) Modern types of consumer packaging and food packaging // Journal of biochemical Engineering \& Bioprocess Technology 3: 17-21.

4. Packaging https://www.kp.ru/guide/pishchevajaupakovka.html

5. Doy Pack www.gerelo.dp.ua/index/packet_doy-pack.html

6. Verkhivker Ya G, Miroshnichenko EM (2016) Development of conserva-tion parameters for tomato sauces and ketchups in a polymer container. Electronic scientific journal “Archivist” (RINI) 10: 56-60. 
7. Flaumenbaum BL, Tanchev SS, Grishin MA (1986) Food Preservation Ba-sics: A Textbook. M .: Agropromizdat.

8. Fan-Young AF, Flaumenbaum BL, Zagibalov AF (1980) Technology for preserving fruits, vegetables, meat and fish: a textbook and others. M.: Food industry.

9. Babarin VP (2006) Handbook of sterilization of canned food: a manual. M .: Agropromizdat (2006)

10. Verkhivker Ya G, Miroshnichenko EM (2011) Preservation of toma-to sauces and ketchups in a plastic container of the Doy-Pak type. Science. pr. / Odessa. nat. Acad. grub. Technology 41: 52-54.

11. Verkhivker Ya G, Miroshnichenko EM, Remikh IA (2012) Thermal preservation of food products in polymer containers. Science and Tech-nology 4: 71-72.

12. Retort - packages https://alfapack.com.ua/produktsiya/ retort

13. Retort - packages https://article.unipack.ru/22702/

14. Pilipenko LN, Verkhivker Ya G, Pilipenko IV (2015) Food preserva-tion (microbiology, energy, control): Odessa: WWB, 232.

15. GOST 33837(2016) Polymer packaging for food products. General specifications. Moscow, 2016.

Copyright: (C2020 Yakov G. Verkhivker. This is an open-access article distributed under the terms of the Creative Commons Attribution License, which permits unrestricted use, distribution, and reproduction in any medium, provided the original author and source are credited. 